\title{
Immunity against poliomyelitis in the Netherlands, assessed in 2006 to 2007: the importance of completing
}

\section{a vaccination series}

N A van der Maas (nicoline.van.der.maas@rivm.nl)1, L Mollema ${ }^{1}$, G A Berbers ${ }^{2}$, D M van Rooijen ${ }^{2}$, H G van der Avoort ${ }^{3}$,

M A E Conyn-Van Spaendonck ${ }^{4}, \mathrm{H}$ E de Melker ${ }^{1}, \mathrm{~F}$ R van der Klis ${ }^{2}$

1. Epidemiology and Surveillance, Centre for Infectious Disease Control, National Institute for Public Health and the Environment, Bilthoven, the Netherlands

2. Immunology of Infectious Diseases and Vaccines, Centre for Infectious Disease Control, National Institute for Public Health and the Environment, Bilthoven, the Netherlands

3. Infectious Disease Research, Diagnostics and Screening, Centre for Infectious Disease Control, National Institute for Public Health and the Environment, Bilthoven, the Netherlands

4. Policy and advice, Centre for Infectious Disease Control, National Institute for Public Health and the Environment, Bilthoven, the Netherlands

Citation style for this article:

van der Maas NA, Mollema L, Berbers GA, van Rooijen DM, van der Avoort HG, Conyn-Van Spaendonck MA, de Melker HE, van der Klis FR. Immunity against poliomyelitis in the Netherlands, assessed in 2006 to 2007: the importance of completing a vaccination series. Euro Surveill. 2014;19(7):pii=20705. Available online: http://www.eurosurveillance.org/ViewArticle.aspx?Articleld=20705

Article submitted on 3 September 2013 / published on 20 February 2014

Europe has been declared polio-free since 2002. Here we describe the seroprotection against poliomyelitis in the Dutch population using banked serum samples. Samples from 1,581 inhabitants of eight municipalities with low vaccination coverage (LVC) and an additional 6,386 samples from a nationwide (NS) group (clinical trial number: ISRCTN20164309; collected in 2006-07) were tested for neutralising antibodies (log 2 reciprocal titres (GMT); non-protection <3) against all three poliomyelitis serotypes. Demographic and epidemiological data were used for statistical regression analysis. Seroprevalence in the NS was 94.6\% (type 1), 91.8\% (type 2) and $84.0 \%$ (type 3). Infants (0-7 months-old) had $\geq 80 \%$ seroprevalence for all serotypes. The highest seroprevalence was found in children, with type 1 and type 2 in five year-olds and type 3 in nine to 10 year-olds. In the LVC group, orthodox protestants, many of whom refuse vaccination, showed seroprevalence rates of $64.9 \%$ (type 1), $61.0 \%$ (type 2 ) and $62.1 \%$ (type 3$)$. In the NS group, non-Western immigrants and travellers to non-European continents had higher seroprevalences compared to Western immigrants and travellers within Europe, respectively. The Dutch National Immunisation Programme against poliomyelitis has provided good seroprotection, with high and long-lasting GMTs against all serotypes upon completion. The unvaccinated population remains at risk.

\section{Introduction}

Poliomyelitis is a severe infectious disease caused by poliovirus, an enterovirus with three serotypes (types 1, 2 and 3). In 90-95\% of cases, the infection remains subclinical. In about $1 \%$ of the symptomatic cases, poliovirus invades the central nervous system, leading to muscle weakness and acute flaccid paralysis [1]. In 1988, the World Health Organization (WHO) launched a polio eradication initiative [2]. Since then, large vaccination campaigns have decreased the worldwide number of poliomyelitis cases by more than $99 \%$. However, the WHO's goal of worldwide eradication remains unachieved.

Europe has been classified by the WHO as polio-free since 2002, despite the 2010 epidemic that originated in Tajikistan, because its dissemination was interrupted successfully. The Netherlands, where poliomyelitis has been notifiable since 1924 [3], suffered from a large type1 poliomyelitis epidemic in 1956 and three smaller outbreaks in 1971 (type 1), 1978 (type 1) and 1992-93 (type 3) [4-6]. In all of these smaller outbreaks, export of poliovirus to two polio-free countries, the United States (US) and Canada, occurred, but only during the 1971 and 1978 outbreaks symptomatic cases among unvaccinated individuals in US and Canada were reported. The last two outbreaks were restricted to orthodox protestant individuals, most of whom were refusing vaccination because of religious reasons and living in socio-geographically closely clustered communities. Since 1993, no cases of poliomyelitis have been reported in the Netherlands [8-11]. Currently, the risk of reintroduction of poliovirus to the Netherlands is discussed due to silent circulation of wild poliovirus in Israel and cases of poliomyelitis in Syria $[12,13]$.

Vaccination against poliomyelitis, using trivalent inactivated polio vaccine (IPV), was introduced in the Netherlands in 1957 for all individuals born in 1945 and younger. Vaccination is free of charge for all inhabitants of the Netherlands up to the age of 18 years, and participation in the National Immunisation Programme (NIP) is not mandatory. From 1962 onwards, IPV was 
administered in a combination vaccination strategy, along with the diphtheria, tetanus and whole-cell pertussis vaccine (DTwcP-IPV). Booster vaccinations with DT-IPV at four and nine years of age were added to the NIP in 1965. Initially, infant vaccinations were given at three, four and five months of age, followed by a booster at the age of 11 months, but this schedule was changed to two, three and four months of age in 1999, in response to an upsurge in pertussis [14]. This schedule, i.e. six IPV doses, was in use at the time of this survey (2006-07) and still is. In 2005 the infant doses of whole-cell pertussis vaccine were replaced with the safer acellular pertussis vaccine [15]. Vaccination coverage with the infant vaccinations has been continuously high (>95\%) since 1957 [16].

A first nationwide seroprevalence study, performed in 1995-96, aimed to monitor the immunity of the Dutch population against diseases included in the NIP [17]. A second study was performed in 2006-07 [18]. Comparison between these studies enables us to assess the impact of changes in the vaccination schedule and (the absence of) circulation of microorganisms targeted by the NIP. The first survey showed good seroprotection rates against poliomyelitis in the general population [19]. Here we describe and discuss the protection against poliomyelitis in a representative Dutch population sample, including individuals from municipalities with low vaccination coverage (LCV), for whom banked serum samples and corresponding demographic and epidemiologic data, retrieved in the second serosurvey in 2006-07, were available.

\section{Methods}

\section{Study population and design}

A national NIP sera and data bank was established in 2006-07 to estimate age-specific seroprevalence of antibodies against vaccination-targeted diseases, as described previously $[18,20]$. The specimen- and database includes male and female Dutch inhabitants, 0-79 years-old, from 40 municipalities nationwide (nationwide sample (NS); $n=6,386$ ), with oversampling of the migrant population. In addition, inhabitants from eight LVC municipalities were included $(n=1,518)$. The demographic and epidemiological data included vaccination and travel history, and other known risk factors.

The study protocol was approved by the Medical Ethics Testing Committee of the Foundation of Therapeutic Evaluation of Medicines (METC-STEG) in Almere, the Netherlands (Clinical Trial Number: ISRCTN 20164309). All participants (or the parent/guardian of minors) provided signed informed consent for blood sampling and data gathering via a questionnaire.

\section{Serology}

The serum samples, derived from blood by centrifugation $(10 \mathrm{~min}$ at $1,000 \mathrm{G})$, were retrieved from $-80{ }^{\circ} \mathrm{C}$ storage. Poliovirus neutralising antibody titres against serotypes 1, 2, and 3 were determined in a standard neutralisation test (NT) using Sabin vaccine strains as challenge viruses, as recommended by the WHO [21]. Sera were tested in two-fold dilutions series. Quality control samples consisting of virus control and an inhouse human serum control were added to each plate. Results were expressed as $\log ^{2}$ reciprocal titres and samples were considered protective if NT titres were $\geq 8$ (i.e. $\log ^{2}$ titre $\geq 3$ ) [22].

\section{Statistical analysis}

Seroprevalence and mean $\log ^{2}$ titres, both with $95 \%$ confidence intervals $(95 \% \mathrm{Cl})$, were calculated using a sampling weight for each study participant. For the NS group, results were adjusted for age, sex, ethnicity, degree of urbanisation, and a two-stage cluster sampling, taking into account the strata (five regions) and clusters (40 municipalities). For the LVC group, results were adjusted for age and sex; in addition, the LVC population was stratified by vaccination coverage related to religious denomination, as defined by Ruijs et al [23], with orthodox protestants (including Protestant Congregations in the Netherlands, Old Protestant Congregations, Restored Protestant Church and Protestant Congregations) representing low or intermediate vaccination coverage and non-orthodox protestants (including Protestant Bond, Christian Protestant Churches, other Protestant Christians, and other, no or unknown religion) representing moderate to high vaccination coverage.

Linear regression analysis was performed to study the decline of antibodies in individuals who had received the complete NIP vaccination series, consisting of six IPV-containing vaccinations. As such, this analysis was limited to individuals between 10 and 45 years-old, since the sixth IPV-containing vaccination would have been administered at approximately nine years of age and those older than 45 years would have been born before the current NIP strategy.

Logistic regression analysis was performed on the NS group to assess possible risk factors for non-protection (NT/3), using a multivariate model which included all variables with a $p$-value $<0.2$ already adjusted for age, sex, degree of urbanisation, and geographic region. To maximise comparability between the three serotypes, the full model was applied without backward selection to each serotype. The results are presented as odds ratios (ORs) with $95 \% \mathrm{Cls}$.

All statistical analyses were performed with SAS software (version 9.3) and Microsoft Excel.

\section{Results}

Immunity in the nationwide sample

The seroprevalence in the NS sample was $94.6 \%, 91.8 \%$ and $84.0 \%$ for poliovirus types 1,2 and 3, respectively. Mean $\log ^{2}$ titres were 7.39, 6.96 and 6.04 for the three respective types (Table 1 ). 
For one month-old infants, who were too young to be vaccinated, the seroprevalence (reflecting maternal antibodies) was $83.0 \%$ (type 1), $79.1 \%$ (type 2), and $65.9 \%$ (type 3). These percentages were higher for the two to four month-old infants, who were eligible for vaccination (maximum of three IPV doses), with seroprevalences of $89.2 \%, 83.3 \%$ and $85.6 \%$ for the three serotypes. Owing to waning of antibodies, the seroprevalence percentages decreased thereafter, with the five to 10 month-olds showing $79.7 \%, 80.8 \%$ and $75.0 \%$ for the three serotypes, but increased again in the 11 to 13 month-olds, who were eligible for a booster dose, with seroprevalences of $92.1 \%, 97.4 \%$ and $94.7 \%$ for the three serotypes. The highest rates of seroprevalence for type 1 and type 2 (both 100\%) were found in five year-old children (after the fifth IPV dose at four years of age), and for type $3(95.9 \%)$ in nine to 10 yearolds (after the sixth IPV dose).

Plotting of the mean $\log ^{2}$ titres of infants and children, stratified by age, indicated the positive effect of booster doses at 11 months and at four and nine years of age (Figure 1). In contrast, plotting of the mean $\log ^{2}$ titres of adults showed a gradually declining trend up to the age of 45-49 years, followed by an increase in mean $\log ^{2}$ titre for people born before 1957, who possibly had been in contact with wild-type poliovirus.
The overall seroprevalence and mean $\log ^{2}$ titres of nonWestern immigrants $(n=1,069)$ were higher than those of individuals of Dutch or Western origin $(n=5,317)$. The higher seroprevalence of type 1 and type 2 in the non-Western group was mainly due to higher seroprevalences in children under the age of four years and adults 40 years and older. The increased seroprevalence of type 3 was evenly distributed over the age categories.

\section{Immunity in the low vaccination coverage sample}

The seroprevalence in the LVC sample excluding orthodox protestant persons was $92.9 \%, 90.3 \%$ and $86.1 \%$ for the three respective serotypes, corresponding to a mean $\log ^{2}$ titre of 7.33 (type 1), 6.66 (type 2) and 6.21 (type 3) (Table 1).

For the orthodox protestant sub-category within the overall LVC sample, both seroprevalence and mean $\log ^{2}$ titres were significantly lower; moreover, analysis of immunity against poliomyelitis in four cohorts in this subcategory, based on date of birth, showed the influence of poliomyelitis outbreaks (Table 2). The results indicated that the youngest cohort, individuals born from 1994 onwards, had not been in contact with wild-type poliovirus, whereas two adult cohorts,

\section{TABLE 1}

Seroprevalence rates and mean $\log ^{2}$ titres for poliovirus types 1, 2 and 3, the Netherlands, $2006-07(\mathrm{n}=7,967)$

\begin{tabular}{|c|c|c|c|}
\hline $\begin{array}{l}\text { Poliovirus } \\
\text { serotype }\end{array}$ & Sample & $\begin{array}{c}\mathrm{NT} \geq 3 \\
\%(95 \% \mathrm{Cl})\end{array}$ & $\begin{array}{l}\text { Mean } \log ^{2} \text { titre } \\
\text { mean }(95 \% \mathrm{Cl})\end{array}$ \\
\hline \multirow{5}{*}{ Type 1} & Nationwide sample ${ }^{a}$ & $94.6(93.9-95.3)$ & $7.39(7.32-7.45)$ \\
\hline & Dutch citizens and Western immigrants ${ }^{b}$ & $94.2(93.4-95.0)$ & $7.30(7.22-7.37)$ \\
\hline & Non-Western immigrants ${ }^{c}$ & $97.6(96.7-98.6)$ & $7.83(7.68-7.98)$ \\
\hline & LVC non-orthodox protestants ${ }^{d}$ & $92.9(91.7-94.1)$ & $7.33(7.05-7.60)$ \\
\hline & Orthodox protestants ${ }^{\mathrm{e}}$ & $64.9(57.8-72.1)$ & $5.34(4.68-6.00)$ \\
\hline \multirow{5}{*}{ Type 2} & Nationwide sample ${ }^{a}$ & $91.8(90.9-92.6)$ & $6.96(6.89-7.03)$ \\
\hline & Dutch citizens and Western immigrants ${ }^{b}$ & $91.1(90.3-91.8)$ & $6.84(6.76-6.92)$ \\
\hline & Non-Western immigrants ${ }^{c}$ & $97.1(95.8-98.4)$ & $7.57(7.42-7.72)$ \\
\hline & LVC non-orthodox protestants ${ }^{d}$ & $90.3(87.8-92.7)$ & $6.66(6.43-6.88)$ \\
\hline & Orthodox protestants ${ }^{\mathrm{e}}$ & $61.0(50.5-71.4)$ & $4.86(4.28-5.45)$ \\
\hline \multirow{5}{*}{ Type 3} & Nationwide sample ${ }^{a}$ & $84.0(82.9-85.1)$ & $6.04(5.96-6.11)$ \\
\hline & Dutch citizens and Western immigrants ${ }^{b}$ & $83.2(82.2-84.1)$ & $5.91(5.82-5.99)$ \\
\hline & Non-Western immigrants ${ }^{c}$ & $90.7(88.9-92.5)$ & $6.68(6.51-6.86)$ \\
\hline & LVC non-orthodox protestants $^{d}$ & $86.1(83.6-88.6)$ & $6.21(5.94-6.48)$ \\
\hline & Orthodox protestants ${ }^{\mathrm{e}}$ & $62.1(54.5-69.7)$ & $4.71(4.21-5.21)$ \\
\hline
\end{tabular}

$\mathrm{CI}$ : confidence interval; NT: neutralisation test; LVC: low vaccination coverage.

\footnotetext{
${ }^{a} n=6,386$.

${ }^{b} \mathrm{n}=5,317$.

${ }^{\mathrm{c}} \mathrm{n}=1,069$.

${ }^{\mathrm{d}} \mathrm{n}=1,038$.

e $n=480$.
} 
Seroprevalence and mean $\log ^{2}$ titres for poliovirus types 1,2 and 3 in the nationwide sample, stratified by age, the Netherlands, 2006-07 $(n=6,386)$

A. Immunity against poliovirus type 1

- $N T \geq 3 \quad$ mean $\log ^{2}$ titre

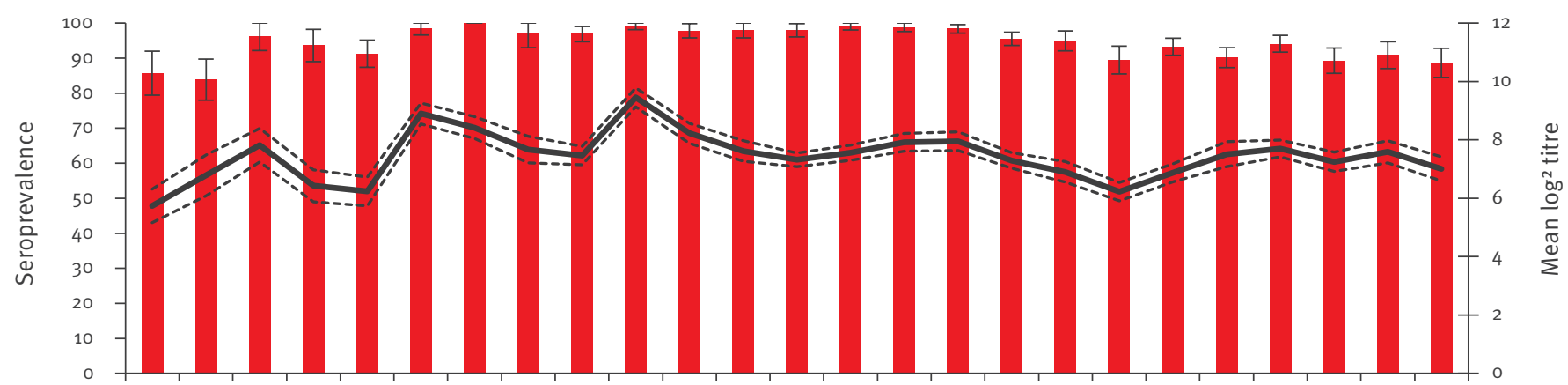

B. Immunity against poliovirus type 2

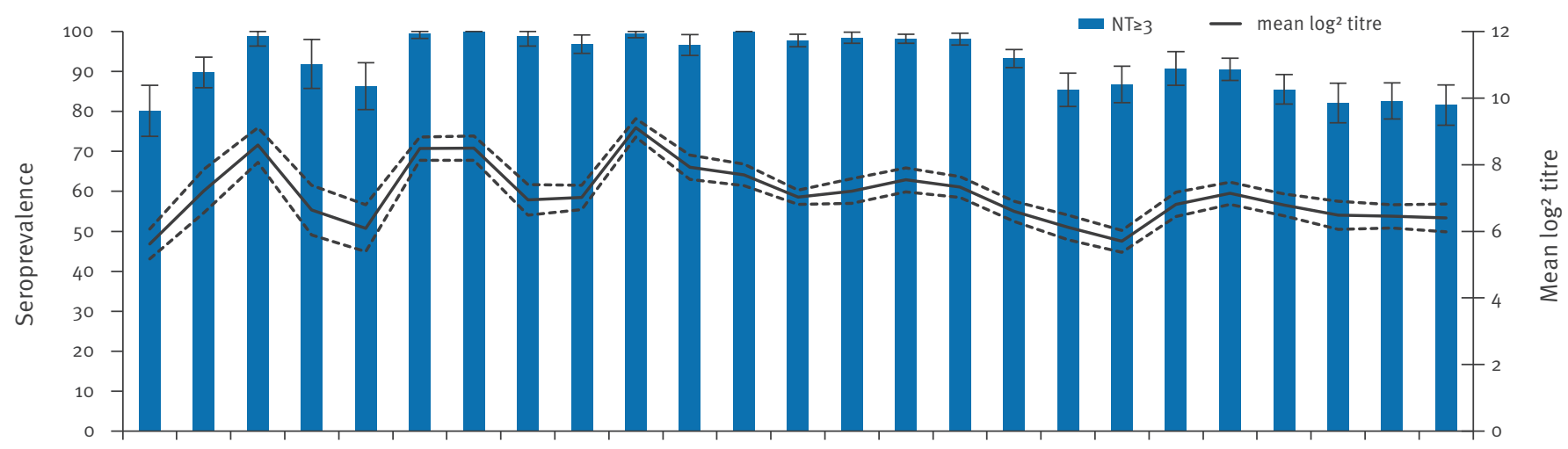

C. Immunity against poliovirus type 3

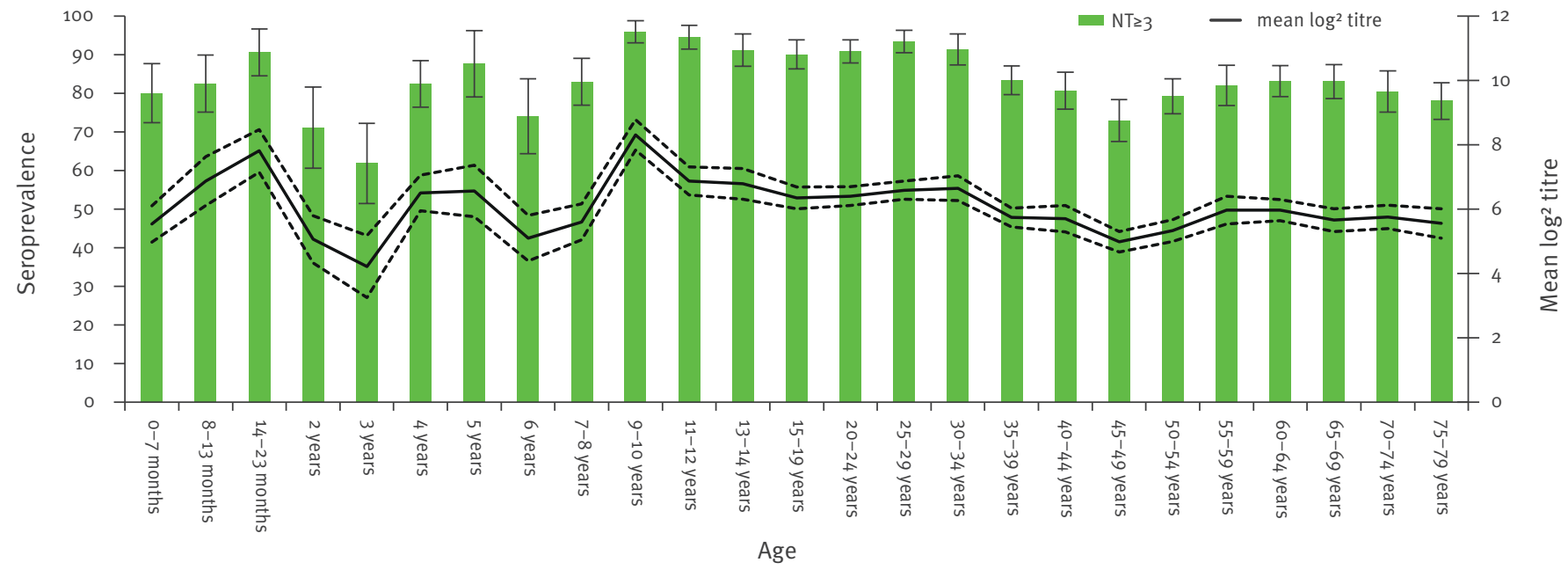

NT: neutralisation assay. 


\section{TABLE 2}

Seroprevalence rates and mean $\log ^{2}$ titres for poliovirus types 1, 2 and 3 in orthodox protestants, stratified by age, the Netherlands, 2006-07 $(n=480)$

\begin{tabular}{|c|c|c|c|}
\hline $\begin{array}{l}\text { Poliovirus } \\
\text { serotype }\end{array}$ & Cohort, by birth date & $\begin{array}{c}\mathrm{NT} \geq 3 \\
\%(95 \% \mathrm{Cl})\end{array}$ & $\begin{array}{c}\text { Log2 titre } \\
\text { mean }(95 \% \mathrm{Cl})\end{array}$ \\
\hline \multirow{4}{*}{ Type 1} & $\geq 1$ Jan $1994^{\mathrm{a}}$ & $49.7(37.6-61.8)$ & $4.36(3.59-5.13)$ \\
\hline & $\geq 1$ Jan1979 and <1 Jan $1994^{\mathrm{b}}$ & $52.8(36.9-68.8)$ & $4.59(3.50-5.68)$ \\
\hline & $\geq 1$ Jan 1957 and $<1$ Jan $1979^{c}$ & $72.9(54.6-91.2)$ & $5.77(4.41-7.14)$ \\
\hline & $<1$ Jan $1957^{d}$ & $80.3(72.2-88.3)$ & $6.40(5.56-7.24)$ \\
\hline \multirow{4}{*}{ Type 2} & $\geq 1$ Jan $1994^{\mathrm{a}}$ & $51.0(39.5-62.5)$ & $4.33(3.66-5.00)$ \\
\hline & $\geq 1$ Jan 1979 and $<1$ Jan $1994^{b}$ & $60.8(45.2-76.4)$ & $4.83(3.65-6.01)$ \\
\hline & $\geq 1$ Jan 1957 and $<1$ Jan $1979^{c}$ & $56.2(41.4-70.9)$ & $4.61(3.63-5.60)$ \\
\hline & $\ll 1$ Jan $1957^{d}$ & $79.0(63.0-95.0)$ & $5.83(4.94-6.72)$ \\
\hline \multirow{4}{*}{ Type 3} & $\geq 1 \operatorname{Jan} 1994^{\mathrm{a}}$ & $48.2(36.9-59.5)$ & $3.99(3.14-4.84)$ \\
\hline & $\geq 1$ Jan 1979 and $<1$ Jan $1994^{b}$ & $68.7(51.8-85.6)$ & $5.51(4.40-6.61)$ \\
\hline & $\geq 1$ Jan 1957 and <1 Jan $1979^{c}$ & $61.7(45.2-78.3)$ & $4.42(3.57-5.27)$ \\
\hline & $\ll 1 \operatorname{Jan} 1957^{\mathrm{d}}$ & $71.1(63.2-79.0)$ & $5.12(4.47-5.77)$ \\
\hline
\end{tabular}

$\mathrm{Cl}$ : confidence interval; NT: neutralisation test.

a $n=190$, no wild-type virus circulating.

${ }^{\mathrm{b}} \mathrm{n}=87$, type 3 outbreak in 1992-93.

${ }^{\mathrm{c}} \mathrm{n}=100$, type 1 outbreaks in 1971 and 1978 .

${ }^{d} n=103$, wild-type virus circulating.

\section{FIGURE 2}

Poliovirus mean $\log ^{2}$ titres in 10 to 44 year-olds in the nationwide sample who completed the NIP vaccination series with no revaccinations, stratified by age, the Netherlands, 2006-07 $(n=1,260)$

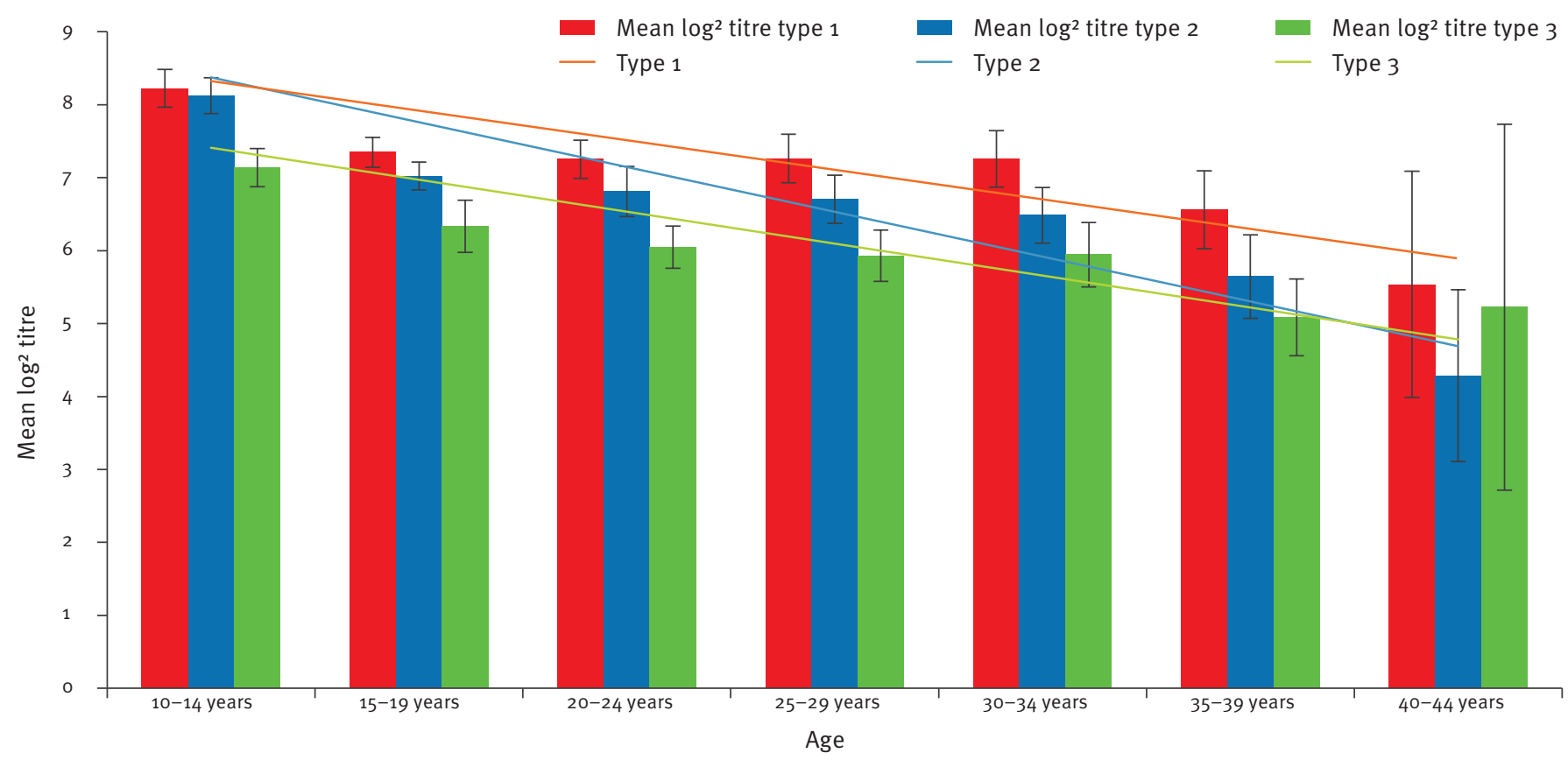

NIP: National Immunisation Programme. 
i.e. individuals born 1979-93 and 1957-78, had been in contact with type 3 and type 1 . This is in agreement with the recorded serotype-specific outbreaks that occurred in 1992-93 and in 1971 and 1978 [6,9]. These outbreaks were controlled with trivalent (1992-93) and monovalent $(1971,1978)$ live attenuated oral polio vaccine (OPV), which possibly also contributed to the observed seroprevalence rates. The cohort born before 1957 lived in the era before large-scale immunisation and therefore probably encountered wild-type virus regularly, as reflected in the moderate to high seroprevalence rates.

\section{Persistence of antibodies in relation to} completion of the poliovirus vaccination strategy in the Dutch National Immunisation Programme

For the NS cohort of 10 to 44 year-olds who had completed the normal immunisation schedule of six IPVcontaining vaccinations by the age of nine years, and had not obtained any extra polio antigen-containing vaccinations $(n=1,260)$, the seroprevalence percentages were $98.8 \%$ (type 1), 97.5\% (type 2) and 90.9\% (type 3). Plotting of the mean $\log ^{2}$ titres showed a decreasing trend with age for all serotypes, but the titres remained well above the protection cut-off of 3 , indicating that seroprotection had been achieved (Figure 2). Linear regression analysis to assess the relation between mean $\log ^{2}$ titre and age yielded the following slopes: type $1,-0.06(95 \% \mathrm{Cl}:-0.07$ to $-0.04)$, type $2,-0.09(95 \% \mathrm{Cl}:-0.10$ to -0.08$)$ and type 3, -0.07 (95\% Cl: -0.09 to -0.05$)$.

\section{Demographic and vaccination-related risk factors of non-protection}

The multivariate logistic regression analysis of risk factors for a non-protective antibody level (NT<3) in the overall NS cohort is presented in Table 3. The lowest seroprevalence for type 1 and type 2 was found in the o year-old infants, while the lowest seroprevalence for type 3 was found in the one to four year-olds. Furthermore, non-Western immigrants had higher seroprevalences than Western immigrants or individuals of Dutch origin. Likewise, the cohort who had travelled to Asia, Africa, or South and Central America had higher seroprevalences than the cohort who reported not having travelled to these continents. The cohort that reported practicing a religion that is associated with vaccination refusal had lower seroprevalences than the cohort that did not belong to these religious groups.

The cohort that had received their last polio antigencontaining vaccination more than 10 years (type 3 ) or more than 20 years (types 1 and 2) before sampling, or who had never received the vaccination, were at increased risk of having a non-protective antibody level compared to the cohort that had received their last vaccination less than one year before sampling. An increased risk for a non-protective antibody level was also found for individuals with medium-level (types 1 and 2) or high-level (types 1 and 3) education, compared with those with low-level education. Finally, individuals who had started but not completed the NIP vaccination series, i.e. those who had received only two to five polio antigen-containing vaccinations, were found to be at higher risk for non-protective antibody levels than the individuals who had completed the NIP vaccination series, although the difference in risk for serotype 2 did not reach statistical significance.

\section{Discussion}

The serosurvey described herein, using samples and data obtained in 2006-07 from across the country, showed that the general population of the Netherlands had an overall high poliovirus vaccination coverage, with protective antibody levels (NT $\geq 3$ ) being at $>90 \%$ for serotypes 1 and 2 and slightly less (84\%) for serotype 3. The seroprotection levels in the youngest population showed a trend of good adherence to the recommended initial vaccination schedule in early life; furthermore, analysis of long-term protection against all three serotypes indicated the benefit of completing the recommended vaccination series, starting in early life and receiving boosters in later childhood. Not surprisingly, the demographic feature of belonging to a religious group that is associated with vaccination refusal was identified as a risk factor for a non-protective antibody level.

These collective results are comparable to those of a previous Dutch seroprevalence study done in 199697 [19], as well as several seroprevalence studies from other countries [24-28]. In particular, the previous Dutch study showed similar age-related trends in seroprotection that correspond to the vaccination schedule and natural exposure, although the seroprevalences found in the current study were overall slightly lower. When comparing the current results from the Netherlands with those from other nations, no remarkable differences were observed for the agespecific trends in seroprevalence of type 1 or type 2 ; however, the seroprevalence trends for type 3 did appear to be lower than those reported in the other studies. Unfortunately, substantial differences in study design precluded direct or systematic comparison of the results, as some of the previous studies used for example age-restricted categories and included individuals with unknown vaccination status. One hypothesis is that the lower seroprevalence of type 3 found in the current study may be related to the whole-cell DTPIPV-Hib vaccine used in the Netherlands until January 2005, which may induce lower antibody titres against serotype 3 , but this needs further study. A possible future third serosurvey will provide more insight into this.

The low seroprevalence rates of the orthodox protestants in the Netherlands highlight the continued risk of poliomyelitis in this community. This was also reflected in the composition of affected persons in the last three natural outbreaks (type 1 in 1971 and 1978 and type 3 in 1992-93) that occurred in the Netherlands [11]. 
TABLE 3

Multivariate logistic regression analysis of risk factors for non-protection against poliovirus types 1, 2 and 3 in the nationwide sample, the Netherlands, 2006-07 $(\mathrm{n}=6,386)$

\begin{tabular}{|c|c|c|c|c|c|c|c|c|}
\hline \multirow{2}{*}{$\begin{array}{l}\text { Demographic- or } \\
\text { vaccination- } \\
\text { related factor }\end{array}$} & \multirow{2}{*}{ Sub-category } & \multirow{2}{*}{$\begin{array}{l}\text { Total } \\
n\end{array}$} & \multicolumn{2}{|c|}{ Poliovirus type 1} & \multicolumn{2}{|c|}{ Poliovirus type 2} & \multicolumn{2}{|c|}{ Poliovirus type 3} \\
\hline & & & $\begin{array}{l}\text { NT<3, } \\
\%\end{array}$ & $\begin{array}{l}\text { Adjusted } \\
\text { OR }(95 \% \mathrm{Cl})\end{array}$ & $\begin{array}{l}\text { NT<3, } \\
\%\end{array}$ & $\begin{array}{l}\text { Adjusted } \\
\text { OR }(95 \% \mathrm{Cl})\end{array}$ & $\begin{array}{l}\text { NT<3, } \\
\%\end{array}$ & $\begin{array}{l}\text { Adjusted } \\
\text { OR }(95 \% \mathrm{Cl})\end{array}$ \\
\hline \multirow{2}{*}{ Sex } & Male & 2,912 & 6.3 & Ref & 8.8 & Ref & 16.7 & Ref \\
\hline & Female & 3,474 & 5.6 & $0.93(0.75-1.16)$ & 8.2 & $0.92(0.76-1.11)$ & 15.2 & $0.90(0.78--1.04)$ \\
\hline \multirow{10}{*}{ Age in years } & 0 & 348 & 19.3 & Ref & 19.3 & Ref & 21.8 & Ref \\
\hline & $1-4$ & 514 & 5.3 & $0.22(0.12-0.40)$ & 6.0 & $0.35(0.19-0.64)$ & 23.5 & $0.69\left(0.44^{-1.08)}\right.$ \\
\hline & $5-9$ & 620 & 1.8 & $0.09(0.04-0.20)$ & 1.3 & $0.09(0.04-0.21)$ & 12.3 & $0.33(0.20-0.55)$ \\
\hline & $10-19$ & 730 & 1.9 & $0.14(0.06-0.37)$ & 1.9 & $0.11(0.04-0.26)$ & 7.8 & $0.18(0.10-0.32)$ \\
\hline & $20-29$ & 712 & 1.1 & $0.06(0.03-0.15)$ & 1.8 & $0.06(0.02-0.13)$ & 7.9 & $0.12(0.07-0.22)$ \\
\hline & $30-39$ & 715 & 3.4 & $0.07(0.03-0.16)$ & 4.8 & $0.06(0.03-0.13)$ & 13.2 & $0.16(0.09-0.28)$ \\
\hline & $40-49$ & 641 & 7.6 & $0.08(0.04-0.17)$ & 13.1 & $0.12(0.06-0.24)$ & 23.1 & $0.17(0.10-0.30)$ \\
\hline & $50-59$ & 714 & 7.8 & $0.09(0.04-0.18)$ & 8.7 & $0.08(0.04-0.16)$ & 18.6 & $0.14(0.08-0.25)$ \\
\hline & $60-69$ & 799 & 7.5 & $0.09(0.04-0.18)$ & 15.0 & $0.16(0.08-0.31)$ & 16.4 & $0.13(0.07-0.22)$ \\
\hline & $70-79$ & 593 & 10.1 & $0.11(0.05-0.23)$ & 17.9 & $0.18(0.09-0.35)$ & 20.4 & $0.15(0.09-0.26)$ \\
\hline \multirow{5}{*}{$\begin{array}{l}\text { Geographic } \\
\text { region }\end{array}$} & North-east & 1,505 & 6.6 & Ref & 9.1 & Ref & 16.0 & Ref \\
\hline & Central & 1,122 & 7.1 & $1.06(0.69-1.63)$ & 9.9 & $1.06(0.72-1.55)$ & 16.3 & $0.97(0.72-1.31)$ \\
\hline & North-west & 1,527 & 5.1 & $0.93(0.67-1.30)$ & 7.0 & $0.91(0.68-1.21)$ & 14.7 & $1.03(0.83-1.27)$ \\
\hline & South-west & 1,125 & 5.0 & $0.62(0.42-0.92)$ & 8.0 & $0.82(0.59-1.15)$ & 15.9 & $0.93(0.72-1.19)$ \\
\hline & South-east & 1,107 & 5.7 & $0.83-0.58-1.19)$ & 8.5 & $0.87(0.64-1.19)$ & 16.8 & $1.05(0.83-1.33)$ \\
\hline \multirow{5}{*}{$\begin{array}{l}\text { Degree of } \\
\text { urbanisation }\end{array}$} & Very high & 1,399 & 5.2 & Ref & 6.5 & Ref & 14.4 & Ref \\
\hline & High & 2,848 & 6.1 & $0.86(0.62-1.19)$ & 8.3 & $1.06(0.79-1.41)$ & 15.5 & $0.92(0.75-1.13)$ \\
\hline & Moderately high & 804 & 6.0 & $0.74(0.49-1.13)$ & 10.3 & $1.20(0.85-1.70)$ & 18.7 & $1.04(0.81-1.35)$ \\
\hline & Low & 589 & 7.3 & $0.79(0.46-1.36)$ & 10.3 & $1.07(0.66-1.74)$ & 16.3 & $0.87(0.60-1.27)$ \\
\hline & Very low & 746 & 5.4 & $0.63(0.40-1.00)$ & 9.1 & $0.99(0.66-1.48)$ & 16.5 & $0.89(0.66-1.19)$ \\
\hline \multirow{2}{*}{ Migrant status } & $\begin{array}{l}\text { Dutch citizens and } \\
\text { Western immigrants }\end{array}$ & 5,317 & 6.6 & Ref & 9.5 & Ref & 17.3 & Ref \\
\hline & $\begin{array}{l}\text { Non-Western } \\
\text { immigrants }\end{array}$ & 1,069 & 2.4 & $0.42(0.26-0.67)$ & 3.0 & $0.47(0.31-0.71)$ & 8.7 & $0.47(0.35-0.62)$ \\
\hline \multirow{4}{*}{$\begin{array}{l}\text { Educational } \\
\text { levela }\end{array}$} & Low & 730 & $4 \cdot 3$ & Ref & 7.5 & Ref & 12.3 & Ref \\
\hline & Medium & 3,138 & 6.4 & $1.57(1.03-2.40)$ & 10.0 & $1.48(1.06-2.08)$ & 16.0 & $1.21(0.93-1.57)$ \\
\hline & High & 2,403 & 5.9 & $1.70(1.09-2.67)$ & 6.8 & $1.26(0.87-1.82)$ & 16.8 & $1.51(1.14-2.00)$ \\
\hline & Unknown & 115 & 1.7 & $0.51(0.12-2.20)$ & 7.0 & $1.25(0.55-2.82)$ & 13.9 & $1.23(0.68-2.24)$ \\
\hline \multirow{2}{*}{$\begin{array}{l}\text { Extent of } \\
\text { vaccination } \\
\text { refusal } \\
\text { according to } \\
\text { religious views }\end{array}$} & None or minor & 6,253 & $5 \cdot 7$ & Ref & 8.3 & Ref & 15.6 & Ref \\
\hline & Moderate to strong & 133 & 15.0 & $2.86(1.66-4.91)$ & 16.5 & $1.97(1.17-3.31)$ & 27.1 & $1.79(1.18-2.72)$ \\
\hline \multirow{8}{*}{$\begin{array}{l}\text { Duration in years } \\
\text { between last } \\
\text { polio-containing } \\
\text { vaccination and } \\
\text { blood sampling }\end{array}$} & 0 & 503 & 10.7 & Ref & 11.1 & Ref & 12.9 & Ref \\
\hline & $1-3$ & 1,201 & 3.3 & $1.46(0.80-2.69)$ & 3.3 & $1.16(0.64-2.10)$ & 13.6 & $2.86(1.84-4.44)$ \\
\hline & $4-9$ & 946 & 1.6 & $1.60(0.68-3.77)$ & 1.1 & $0.80(0.32-1.99)$ & 8.0 & $3.69(2.17-6.26)$ \\
\hline & $10-20$ & 735 & 0.1 & $0.19(0.02-1.54)$ & 1.1 & $0.96(0.36-2.57)$ & 7.8 & $5.25(2.93-9.39)$ \\
\hline & $21-30$ & 407 & 3.0 & $4.47(1.70-11.78)$ & 6.1 & $5.97(2.59-26.58)$ & 12.0 & $7.24(3.87-13.52)$ \\
\hline & 131 & 264 & 11.0 & $9.31(4.13-21.00)$ & 17.1 & $12.54(5.92-26.58)$ & 31.8 & $18.75(10.42-33.74)$ \\
\hline & Unknown & 103 & 1.0 & $0.48(0.06-3.84)$ & 1.9 & $0.83(0.19-3.76)$ & 13.6 & $4.38(2.11-9.12)$ \\
\hline & Not vaccinated & 2,227 & 10.1 & $13.58(5.09-36.24)$ & 15.9 & $5.28(2.46-11.31)$ & 22.7 & $21.44(11.18-41.10)$ \\
\hline \multirow{5}{*}{$\begin{array}{l}\text { Number of } \\
\text { polio antigen- } \\
\text { containing } \\
\text { vaccinations }\end{array}$} & 6 (completed NIP) & 1,498 & 1.3 & Ref & 2.6 & Ref & 8.6 & Ref \\
\hline & $0-1$ & 2,592 & 9.0 & $1.29(0.47-3.55)$ & 14.5 & $1.95(0.99-3.85)$ & 20.3 & $0.85(0.49-1.47)$ \\
\hline & $2-5$ & 1,900 & 6.3 & $2.63(1.31-5.28)$ & 6.2 & $1.04(0.61-1.80)$ & 17.6 & $1.61(1.15-2.26)$ \\
\hline & $\begin{array}{l}6 \text {, including single } \\
\text { IPV or OPV }\end{array}$ & 68 & 4.4 & $1.86(0.47-7.31)$ & 4.4 & $0.48(0.13-1.74)$ & 16.2 & $1.19(0.56-2.53)$ \\
\hline & $\geq 7$ & 328 & 0.6 & $0.61(0.14-2.75)$ & 1.5 & $0.67(0.25-1.81)$ & 4.0 & $0.59(0.32-1.10)$ \\
\hline \multirow{2}{*}{$\begin{array}{l}\text { Travelling } \\
\text { to high-risk } \\
\text { regionsb }\end{array}$} & No & 3,956 & 7.7 & Ref & 11.5 & Ref & 20.0 & Ref \\
\hline & Yes & 2,430 & 2.9 & $0.61(0.46-0.82)$ & 3.5 & $0.44(0.34-0.58)$ & 9.1 & $0.57(0.47-0.68)$ \\
\hline
\end{tabular}

CI: confidence interval; IPV: inactivated polio vaccine; NIP: National Immunisation Programme; NT: neutralisation test; OPV: oral polio vaccine; OR: odds ratio.

a For children younger than 14 years, the mothers' higher educational level was recorded. Low: no education or only primary school; medium: junior technical school, lower general, or intermediate vocational secondary schooling; high: higher vocational, higher general secondary, pre-university, or university schooling.

Asia, Africa, or South and Middle America.

Statistically significant results are indicated by bold font. 
Compared with the first survey, seroprevalence rates in orthodox protestant individuals were even lower in this second survey [19]. Since 1993, no notifications of poliomyelitis have been reported in the Netherlands. In addition, nationwide laboratory and environmental surveillance yielded no signal of poliovirus circulation, so it can be assumed that no boosting opportunities with wild-type poliovirus have occurred in the Netherlands since $1993[9,11]$. It is well known that vaccine-derived polioviruses originating from OPV vaccines represent a possible route of disease introduction into communities without established seroprotection. This threat is especially applicable to communities with close sociogeographical clustering, such as the Dutch orthodox protestants.

The current study also found that individuals who had received their last IPV-containing vaccination more than 20 years before sampling, were at increased risk of having antibody levels below the protective threshold. However, Abbink et al. previously demonstrated memory immunity against poliomyelitis in their study of 400 elderly people who were ineligible for vaccination but who were likely to have encountered wild-type infection earlier in life [29]. Assuming that vaccinationinduced immunity is as effective as natural immunity suggests that adequate vaccination strategies (including initial and booster doses) will produce sufficient and long-term protection.

Another intriguing finding of the current study is that the non-Western immigrant cohort had higher seroprevalence rates and higher mean $\log ^{2}$ titres than the cohort of Dutch citizens and Western immigrants. In contrast, several other studies found no differences $[30,31]$. It is possible that the differential results reflect differences in study populations, including variations in age, country of birth, national vaccination strategies (i.e. vaccine type and schedule), and previous exposure.

In the current study, individuals travelling to Asia, Africa, or Central and South America also showed higher seroprevalence rates than those who did not travel to these continents. Indeed, the dT-IPV vaccination is strongly recommended by travel medicine physicians [32]. Assuming that many travellers decide to get this vaccination before travelling, it is possible that the number of polio-antigen containing vaccinations reported in the Dutch NIP registers collected in this study does not accurately reflect the total number of vaccinations an individual has received. In an attempt to address this potential limitation of the current study design, the study participants were requested to provide their personal vaccination booklets that are kept for such travel purposes; however, we cannot exclude that people may have forgotten to bring this certificate.

Finally, the current study found that higher educational level (of the individual or female parent/guardian of a child) was associated with an increased risk for non-protective antibody levels. This finding seems contradictory to the mass of worldwide studies that have shown higher education to be associated with increased healthcare and higher rates of compliance with health-related policies. In particular, a previous analysis of the Dutch NIP questionnaire indicated that lower socio-economic status (which is generally associated with lower education) was associated with lower participation [33]. Two other studies, assessing the uptake of human papilloma virus vaccination and NIP vaccinations in general, reported a similar link between lower socio-economic status and lower vaccination compliance. Thus, the finding from the current study must be investigated in future studies to determine its validity or underlying causes.

The current study design, using data from both a questionnaire and blood sampling of a large random sample of Dutch inhabitants, affords the possibility to extrapolate results to the general population and to assess the potential risk factors of decreased seroprotection. However, any self-reported data (such as vaccination history) carries a risk of being incomplete or incorrect, and may negatively impact study findings [34]. In addition, the current results may have been impacted by assay-related limitations; for example, the neutralisation test used here and in most seroprevalence studies is recommended by the WHO as the gold standard for detecting viral serotypes, but may yield false positives or negatives and preclude direct comparison between laboratories or between studies $[35,36]$. However, in the current study, the testing of the nearly 8,000 samples was carried out over a period of one year, which may have helped limit the potential influence of dayby-day variability in the testing method and its results. Moreover, an in-house control serum, calibrated to the WHO standard, was included on each test plate. These technical strategies were carried out to help strengthen the results' representation of the current status of immunity against poliomyelitis in the Netherlands.

In conclusion, age-related variations in seroprevalence rates were found in the NS that were related to the Dutch NIP against poliomyelitis. The lowest rates were found in children younger than 14 months, who would be eligible for a maximum of four IPV doses, and the highest rates were found in five year-old children, who would have received five polio-antigen containing vaccinations according to the NIP strategy. Completion of the NIP vaccination series (including all six initial and booster doses) was associated with high and long-lasting seroprotection. In the general population, seroprevalence rates were above the threshold necessary for prevention of poliovirus transmission, estimated at $82-87 \%$ given the condition of homogeneous mixing [37], with the exception of one month-old infants and children between five and 10 months of age. Furthermore, the orthodox protestant community remains at high risk due to their refusal of vaccination. Thus, it is important to continue efforts to increase coverage among this population, and 
improved approaches should be designed with respect to the particular religious arguments that underlie non-compliance with a vaccination programme $[38,39]$. Finally, conducting updated nationwide serosurveys is important to monitor the effects of the recent extended period (since 1993) without wild-type virus challenges, and to assess the efficacy of changes in the immunisation schedule.

\section{Acknowledgments}

This study is entirely funded by the Dutch government.

\section{Conflict of interest}

None declared

\section{Authors' contributions}

Nicoline van der Maas, Liesbeth Mollema and Hester de Melker have done the main data analysis. All authors contributed significantly to additional data analyses and to the preparation of the manuscript.

\section{References}

1. Huisman J, editor. Immunisatie tegen infectieziekten. [Immunisation against infectious diseases]. Alphen aan de Rijn/Brussel: Stafleu; 1984. Dutch.

2. Forty-first Wolrd Health Assembly. Resolutions and decisions. WHA41.28. Global eradication of poliomyelitis by the year 2000. Geneva: World Health Organization; 1988. Available from: http://www.polioeradication.org/Portals/o/Document/ AboutUs/History/WHA.Resolutions.and.Decisions.pdf

3. van Vliet H. Geschiedenis van de meldingsplicht. [History of notification]. Tijdschrift voor infectieziekten. 2009;4(2):51-60. Dutch. Available from: http://www.ariez.nl/DownloadFile. lynkx?guid=b8ffbdc3-fbeo-4d1f-aoac-90a6b3c73c7d

4. Bijkerk H. Poliomyelitis epidemic in the Netherlands, 1978. Dev Biol Stand. 1979;43:195-206.

5. Bijkerk H, Draaisma FJ, Landheer T, van Os M. [Poliomyelitis epidemic in Staphorst]. Ned Tijdschr Geneeskd. 1972;116(14):549-58. Dutch.

6. Oostvogel PM, van Wijngaarden JK, van der Avoort HG, Mulders MN, Conyn-van Spaendonck MA, Rumke HC, et al. Poliomyelitis outbreak in an unvaccinated community in The Netherlands, 1992-93. Lancet. 1994;344(8923):665-70. http://dx.doi. org/10.1016/S0140-6736(94)92091-5

7. Bijkerk H, Draaisma FJ, van der Gugten AC, van Os M. [The poliomyelitis epidemic in 1978]. Ned Tijdschr Geneeskd. 1979;123(39):1700-14. Dutch.

8. Rümke HC, Oostvogel PM, Van Steenis G, Van Loon AM. Poliomyelitis in The Netherlands: a review of population immunity and exposure between the epidemics in 1978 and 1992. Epidemiol Infect. 1995;115(2):289-98. http://dx.doi. org/10.1017/So950268800058416

9. Schaap GJ, Bijkerk H, Coutinho RA, Kapsenberg JG, van Wezel $\mathrm{AL}$. The spread of wild poliovirus in the well-vaccinated Netherlands in connection with the 1978 epidemic. Prog Med Virol. 1984;29:124-40.

10. Centers for Disease Control and Prevention (CDC). Isolation of wild poliovirus type 3 among members of a religious community objecting to vaccination--Alberta, Canada, 1993. MMWR Morb Mortal Wkly Rep. 1993;42(17):337-9.

11. Conyn-van Spaendonck MA, Oostvogel PM, van Loon AM, van Wijngaarden JK, Kromhout D. Circulation of poliovirus during the poliomyelitis outbreak in The Netherlands in 1992-1993. Am J Epidemiol. 1996;143(9):929-35. http://dx.doi.org/10.1093/ oxfordjournals.aje.aoo8836

12. Anis E, Kopel E, Singer SR, Kaliner E, Moerman L, Moran-Gilad $\mathrm{J}$, et al. Insidious reintroduction of wild poliovirus into Israel, 2013. Euro Surveill. 2013;18(38):pii: 20586
13. World Health Organization (WHO). Polio in the Syrian Arab Republic - update. Geneva: WHO; 2013. Available from: http:// www.who.int/csr/don/2013_11_11polio/en/

14. de Melker HE, Schellekens JF, Neppelenbroek SE, Mooi FR, Rumke HC, Conyn-van Spaendonck MA. Reemergence of pertussis in the highly vaccinated population of the Netherlands: observations on surveillance data. Emerg Infect Dis. 2000;6(4):348-57. http://dx.doi.org/10.3201/ eido604.000404

15. Gezondheidsraad. Vaccinatie tegen kinkhoest. [Vaccination against pertussis]. Den Haag: Gezondheidsraad; 2004. Dutch. Available from: http://www.gezondheidsraad.nl/sites/default/ files/0404nadden.pdf

16. Van Lier A. Vaccinatiegraad Rijksvaccinatieprogramma Nederland; Verslagjaar 2011. [Vaccination coverage National Immunisation Programme of the Netherlands; year of report 2011]. Bilthoven: National Institute for Public Health and the Environment; 2011. Dutch. Available from: http://www.rivm.nl/ dsresource?objectid=rivmp:47976\&type $=$ org \&disposition $=$ inli ne\&ns_nc $=1$

17. De Melker HE, Conyn-van Spaendonck MA. Immunosurveillance and the evaluation of national immunization programmes: a population-based approach. Epidemiol Infect. 1998;121(3):63743. http://dx.doi.org/10.1017/So950268898001587

18. van der Klis FR, Mollema L, Berbers GA, de Melker HE, Coutinho RA. Second national serum bank for populationbased seroprevalence studies in the Netherlands. Neth J Med. 2009;67(7):301-8.

19. Conyn-Van Spaendonck MA, de Melker HE, Abbink F, Elzinga-Gholizadea N, Kimman TG, van Loon T. Immunity to poliomyelitis in The Netherlands. Am J Epidemiol. 2001;153(3):207-14. http://dx.doi.org/10.1093/aje/153.3.207

20. Mollema L, de Melker HE, Hahné SJ, van Weert JW, Berbers G, van der Klis FR. PIENTER 2-project: second research project on the protection against infectious diseases offered by the national immunization programme in the Netherlands. Bilthoven: National Institute for Public Health and the Environment; 2009. Report No.: 230421001. Available from: http://www.rivm.nl/dsresource?objectid=rivmp:11329\&type $=0$ rg\&disposition=inline\&ns_nc=1

21. World Health Organization (WHO). Guidelines for WHO/ EPI collaborative studies on poliomyelitis: standard procedure for determining immunity to poliovirus using the microneutralization test . Geneva: WHO; 1993. Available from: http://apps.who.int/iris/bitstream/10665/70486/1/WHO_EPI_ GEN_93.9_eng.pdf?ua=1

22. Robertson SE. The immunological basis for immunisation. Module 6. Poliomyelitis. Geneva: World Health Organization; 1993 WHO/EPI/GEN/9316. Available from: http://www.who.int/ ihr/polio1993en.pdf

23. Ruijs WL, Hautvast JL, van Ansem WJ, Akkermans RP, van't Spijker K, Hulscher ME, et al. Measuring vaccination coverage in a hard to reach minority. Eur J Public Health. 2012;22(3):35964. http://dx.doi.org/10.1093/eurpub/ckro81

24. Diedrich S, Claus H, Schreier E. Immunity status against poliomyelitis in Germany: determination of cut-off values in International Units. BMC Infect Dis. 2002;2:2. http://dx.doi. org/10.1186/1471-2334-2-2

25. Frantzidou F, Diza E, Halkia D, Antoniadis A. A seroprevalence study of poliovirus antibody in the population of northern Greece. Clin Microbiol Infect. 2005;11(1):68-71. http://dx.doi. org/10.1111/j.1469-0691.2004.00998.x

26. Nates SV, Martinez LC, Barril PA, Ferreyra LJ, Giordano MO, Masachessi G, et al. Long-lasting poliovirus-neutralizing antibodies among Argentinean population immunized with four or five oral polio vaccine doses 1 month to 19 years previously. Viral Immunol. 2007;20(1):3-10. http://dx.doi.org/10.1089/ vim.2006.0071

27. Tafuri S, Prato R, Martinelli D, Calvario A, Bozzi A, Labianca $M$, et al. Serological survey on immunity status against polioviruses in children and adolescents living in a border region, Apulia (Southern Italy). BMC Infect Dis. 2008;8:150. http://dx.doi.org/10.1186/1471-2334-8-150

28. Li XM, Zhang HR, Wang YM. [Analysis of polio antibody levels in healthy population in Beijing in 2007]. Zhongguo Yi Miao He Mian Yi. 2009;15(3):245-8.

29. Abbink F, Buisman AM, Doornbos G, Woldman J, Kimman TG, Conyn-van Spaendonck MA. Poliovirus-specific memory immunity in seronegative elderly people does not protect against virus excretion. J Infect Dis. 2005;191(6):990-9. http:// dx.doi.org/10.1086/427810

30. Diedrich S, Schreier E. [The German Health Interview and Examination Survey for Children and Adolescents (KiGGS): state of immunity against poliomyelitis in German children]. Bundesgesundheitsblatt Gesundheitsforschung 
Gesundheitsschutz. 2007;50(5-6):771-4. German. http:// dx.doi.org/10.1007/s00103-007-0239-1

31. Affanni P, Veronesi L, Rizziero S, Bizzoco S, Bracchi MT, Tanzi ML. Status of immunity against poliomyelitis: a study among European and extra-European young immigrants living in Parma. Acta Biomed. 2005;76(3):157-63.

32. Landelijk Coördinatiecentrum Reizigersadvisering (LCR). Vaccinaties. [Vaccinations]. Amsterdam: LCR. [Accessed Feb 2014]. Dutch. Available from: http://www.lcr.nl/Vaccinaties

33. Mollema L, Wijers N, Hahne SJ, van der Klis FR, Boshuizen HC, de Melker HE. Participation in and attitude towards the national immunization program in the Netherlands: data from population-based questionnaires. BMC Public Health. 2012;12:57. http://dx.doi.org/10.1186/1471-2458-12-57

34. Steens A, Mollema L, Berbers GA, van Gageldonk PG, van der Klis FR, de Melker HE. High tetanus antitoxin antibody concentrations in the Netherlands: a seroepidemiological study. Vaccine. 2010;28(49):7803-9. http://dx.doi. org/10.1016/j.vaccine.2010.09.036

35. Wood DJ, Heath AB. Comparability of poliovirus neutralizing antibody tests. Biologicals. 1992;20(4):293-300. http://dx.doi. org/10.1016/S1045-1056(05)80050-8

36. Albrecht P, van Steenis G, van Wezel AL, Salk J. Standardization of poliovirus neutralizing antibody tests. Rev Infect Dis. 1984;6 Suppl 2:S540-4. http://dx.doi.org/10.1093/clinids/6. Supplement_2.S540

37. Anderson RM, May RM, editors. Infectious diseases of humans: dynamics and control. New York Oxford University Press; 1991.

38. Ruijs WL, Hautvast JL, van ljzendoorn G, van Ansem WJ, van der Velden K, Hulscher ME. How orthodox protestant parents decide on the vaccination of their children: a qualitative study. BMC Public Health. 2012;12:408. http://dx.doi. org/10.1186/1471-2458-12-408

39. Ruijs WL, Hautvast JL, van 't Spijker K, van der Velden K, Hulscher ME. Information on vaccination: meeting the needs of unvaccinated youngsters in the Netherlands. Eur J Public Health. 2011;21(3):344-6. http://dx.doi.org/10.1093/eurpub/ ckq172 